\title{
A Salt Metathesis Route to Ruthenium Carbene Complex Isomers with Pyridine Dicarboxamide-derived Chelate Pincer Ligands
}

Carolin Wallenhorst ${ }^{\mathrm{a}}$, Kirill V. Axenov ${ }^{\mathrm{a}}$, Gerald Kehr ${ }^{\mathrm{a}}$, Joseph S. M. Samec ${ }^{\mathrm{b}}$, Roland Fröhlich ${ }^{\mathrm{a}}$, and Gerhard Erker ${ }^{\mathrm{a}}$

a Organisch-Chemisches Institut der Universität Münster, Corrensstraße 40, D-48149 Münster,

Germany

b The Arnold and Mabel Beckman Laboratory of Chemical Synthesis, Division of Chemistry and Chemical Engineering, California Institute of Technology, Pasadena, California 91125, USA

Reprint requests to Prof. Dr. G. Erker. Fax: +49 251-83 36503. E-mail: erker@ uni-muenster.de

Z. Naturforsch. 2007, 62b, 783-790; received January 27, 2007

Reaction of the doubly deprotonated pyridine 2,6-dicarboxamido ligand (1) with $\left(\mathrm{PCy}_{3}\right)_{2} \mathrm{Cl}_{2}$ $\mathrm{Ru}=\mathrm{CHPh}(\mathbf{3 a})$ in THF gave a mixture of $($ lig) $(\mathrm{PCy}) \mathrm{Ru}=\mathrm{CHPh}$ isomers (4). The pentane soluble N,N,O-4 isomer was isolated by extraction and characterized by X-ray diffraction. The O,N, O-4 isomer was identified in the residue. Single crystals of the closely related complex (lig)(NHC) $\mathrm{Ru}=\mathrm{CHPh}, \mathrm{O}, \mathrm{N}, \mathrm{O}-\mathbf{5}$, were obtained from the reaction of $\mathbf{1}$ with $(\mathrm{NHC})\left(\mathrm{PCy}_{3}\right) \mathrm{Cl}_{2} \mathrm{Ru}=\mathrm{CHPh}(3 \mathbf{b})$ and used for the X-ray crystal structure analysis of the system.

Key words: Chelate Ligand, Salt Metathesis, Ruthenium Carbene Complexes, Isomeric Coordination Compounds

\section{Introduction}

Ruthenium-based carbene complexes have found numerous applications in $e . g$. organic synthesis, polymer chemistry, and organometallic chemistry [1]. Sometimes, pyridine-based auxiliary ligands have a marked influence on the performance of such metathesis catalysts [2]. We have described a pyridine dicarboxamide pathway to chelate pincer ligand $\mathrm{Ru}$-carbene systems (2). These systems were disappointing with regard to catalysis, but showed some interesting stereochemical features [3]. Our synthesis followed conventional preparative pathways [4] (Scheme 1): Reaction of $\left(\mathrm{PPh}_{3}\right)_{3} \mathrm{RuCl}_{2}$ with the dianionic ligand system $\mathbf{1}$ (employed as the dipotassium salt), followed by treatment with phenyldiazomethane resulted in the forma- tion of $\mathbf{2}$, formed here as a mixture of two regioisomers, N,N,O-2 and O,N,O-2. Single crystals of each of the isomers were eventually obtained and the pair of products characterized by X-ray crystal structure analyses [3].

We have now succeeded in preparing related $\mathrm{PCy}_{3}-$ or NHC-derived pincer ligand $[\mathrm{Ru}]=\mathrm{CHPh}$ complexes in a more direct way by salt metathesis reaction [5] between the reagent 1 and $\left(\mathrm{PCy}_{3}\right)_{2} \mathrm{Cl}_{2} \mathrm{Ru}=\mathrm{CHPh}(\mathbf{3 a})$ [6] or $(\mathrm{NHC})\left(\mathrm{PCy}_{3}\right) \mathrm{Cl}_{2} \mathrm{Ru}=\mathrm{CHPh}(3 \mathbf{b})$ [7], respectively. Although the resulting complexes were rather sensitive and some of the reactions apparently rather complicated and sometimes unselective, we were able to isolate and characterize a key compound in this series, namely $\mathrm{N}, \mathrm{N}, \mathrm{O}-\mathbf{4}$, and to achieve some information about its $\mathrm{O}, \mathrm{N}, \mathrm{O}-\mathbf{4}$ isomer. In addition, a related

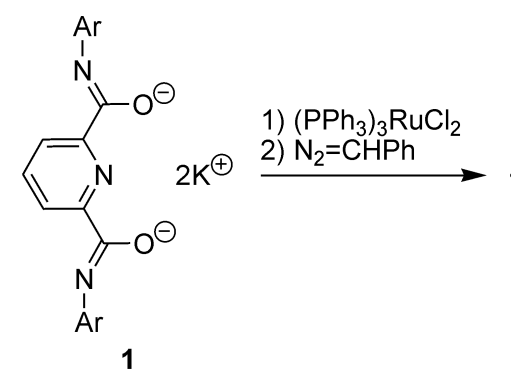

$\mathrm{Ar}=-2,6$-diisopropylphenyl

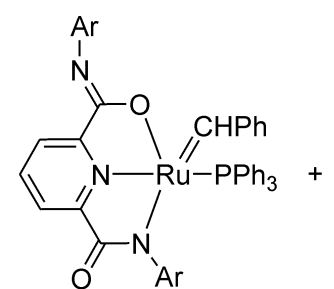

$\mathrm{N}, \mathrm{N}, \mathrm{O}-2$

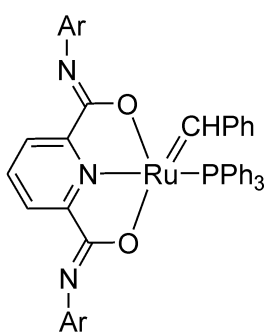

$\mathrm{O}, \mathrm{N}, \mathrm{O}-2$

0932-0776 / 07 / 0600-0783 \$ 06.00 @ 2007 Verlag der Zeitschrift für Naturforschung, Tübingen · http://znaturforsch.com 


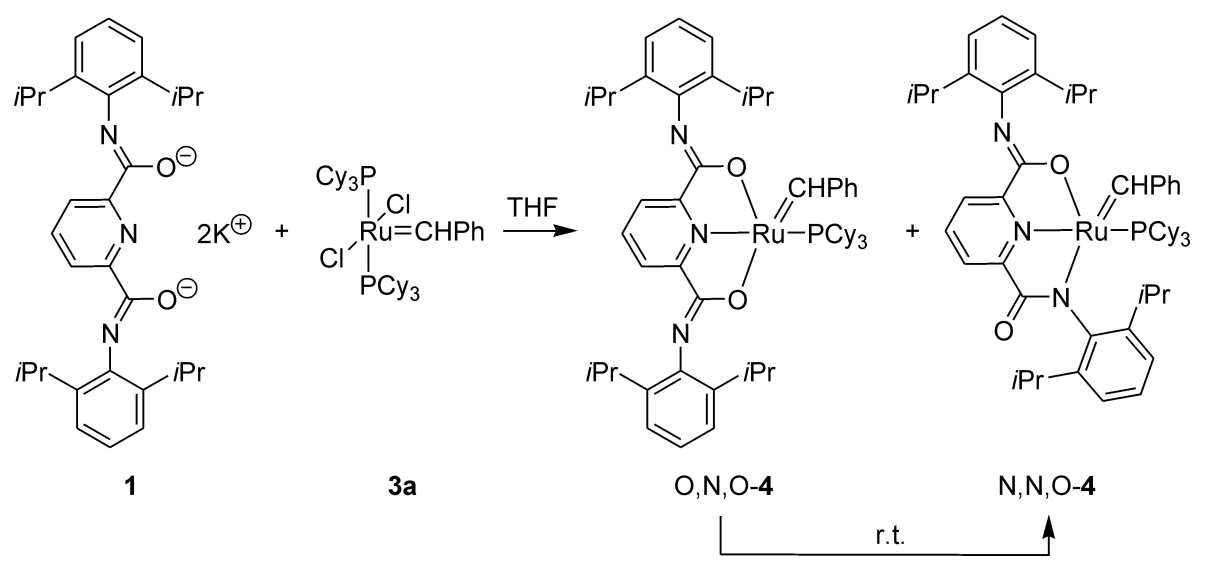

Scheme 2.

(NHC)-derived system, O,N,O-5, was characterized by $\mathrm{X}$-ray diffraction. Some details of this study are described in the following account.

\section{Results and Discussion}

The tridentate chelate ligand system was prepared as described previously [3] by treatment of pyridine2,6-dicarboxylic acid dichloride with two equivalents of 2,6-diisopropylaniline followed by deprotonation with potassium hydride. Following a series of test reactions under various reaction conditions, we eventually reacted the dipotassium salt $\mathbf{1}$ with $\left(\mathrm{PCy}_{3}\right)_{2} \mathrm{Cl}_{2} \mathrm{Ru}=$ $\mathrm{CHPh}(3 a)$ in tetrahydrofuran for $2 \mathrm{~d}$ at ambient temperature. Workup including extraction with pentane (as described in the Experimental Section) eventually gave a single brown solid product, isolated in ca. $30 \%$ yield. It was characterized by $\mathrm{C}, \mathrm{H}$ elemental analysis and by a detailed NMR study. On this basis we have assigned to it the structure of the N,N,O-4 isomer (Scheme 2).

The isolated compound (N,N,O-4) shows a single ${ }^{31} \mathrm{P}$ NMR resonance at $\delta=26.3$ (in $\left[\mathrm{D}_{6}\right]$ benzene) and a very characteristic carbene $=\mathrm{CH}(\mathrm{Ph}){ }^{1} \mathrm{H}$ NMR signal at $\delta=19.45\left(\mathrm{~d},{ }^{3} J_{\mathrm{P}, \mathrm{H}}=24.1 \mathrm{~Hz}, 1 \mathrm{H}\right.$; see for a comparison: N,N,O-2: $\delta=18.23(\mathrm{~d}, 28.7 \mathrm{~Hz})$ [3]). The corresponding ${ }^{13} \mathrm{C}$ NMR carbene carbon signal of N,N,O-4 occurs at $\delta=296.1(\mathrm{~d}, 13.6 \mathrm{~Hz})$. Due to its unsymmetrical coordination mode there are three separate $s p^{2}-\mathrm{CH}$ resonances of the pyridine residue $(\delta=7.82(\mathrm{~d}), 7.76(\mathrm{~d}), 6.84(\mathrm{t})$, each $1 \mathrm{H})$ with corresponding ${ }^{13} \mathrm{C}$ NMR features at $\delta=125.0,124.2$ and 137.9. NMR features of a pair of non-identical 2,6-diisopropylphenyl substituents are observed. Their typical appearance indicates that both their arene planes are oriented normal to the pyridine-dicarboxyl-

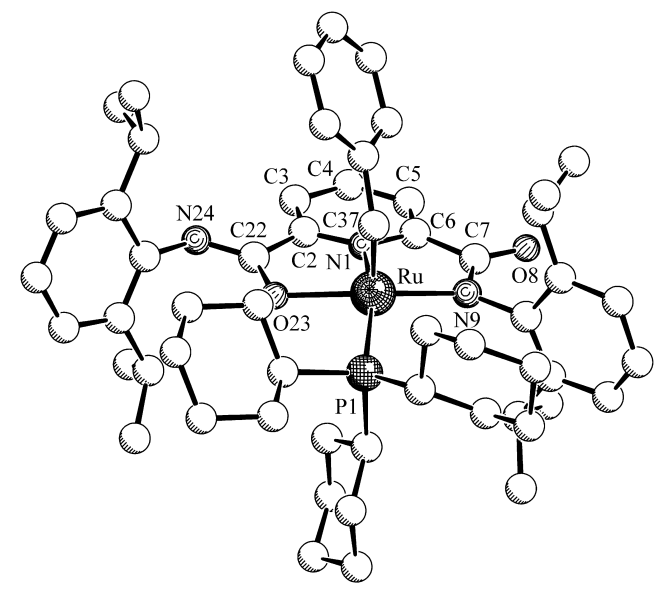

Fig. 1. Molecular structure of N,N,O-4 (hydrogen atoms omitted for clarity).

ato chelate ligand plane and that rotation around the corresponding $\mathrm{N}-\mathrm{C}$ vectors is slow on the NMR time scale. This leads to two different axially chiral subunits [9] at the periphery of the central ligand plane and, consequently, we have observed a total of four isopropyl- $\mathrm{CH}$ septets for N,N,O-4 (at $\delta=3.71 / 2.51$ and 2.83/3.33; cf. the N,N,O-2 reference: $\delta=3.54,3.25$, $2.94,2.31)$. The attached isopropyl-methyl groups are in each case pairwise diastereotopic, which leads to the observation of a total of eight isopropyl- $\mathrm{CH}_{3}{ }^{1} \mathrm{H}$ NMR doublets for $\mathrm{N}, \mathrm{N}, \mathrm{O}-4$ ( $\delta=1.55 / 1.46,1.12 / 0.78$, and $1.11 / 0.77,1.43 / 1.39)$. The carboxamido ${ }^{13} \mathrm{C}$ NMR signals of N,N,O-4 were found at $\delta=174.6$ and $\delta=$ 163.5. The signals of the coordinated $\mathrm{PCy}_{3}$ ligand were broad and could, therefore, not be located with sufficient accuracy.

Complex N,N,O-4 was characterized by $\mathrm{X}$-ray diffraction (single crystals from pentane). It features 

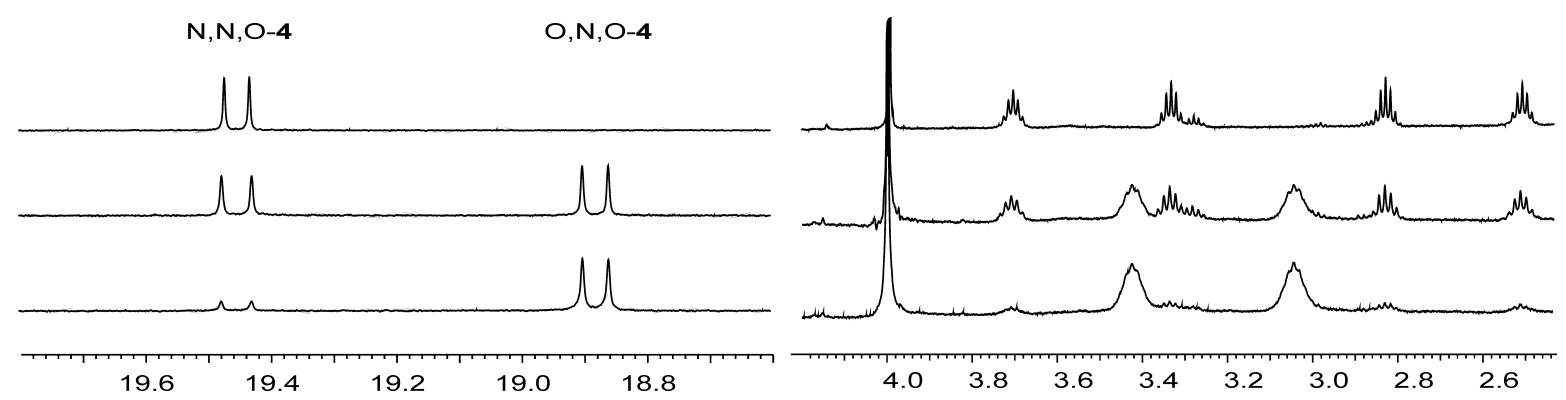

Fig. 2. ${ }^{1} \mathrm{H}$ NMR spectral (600 MHz, $\mathrm{C}_{6} \mathrm{D}_{6}$, with ferrocene as internal standard at $\delta=4.00$ ) evolution of the rearrangement of O,N,O-4 to N,N,O-4 at $298 \mathrm{~K}$. Depicted are the regions for the carbene protons (left) and the methine protons of the $i \mathrm{Pr}$ groups (right): bottom trace: starting point; middle trace: after $8 \mathrm{~h}$, top trace: after $2 \mathrm{~d}$.

an N,N,O-coordination of the tridentate chelate ligand to ruthenium (Fig. 1). The coordination geometry at the pentacoordinate Ru center is distorted squarepyramidal. The $=\mathrm{CHPh}$ carbene ligand forms the apex of the square-pyramidal framework with a $\mathrm{Ru}-\mathrm{C} 37$ bond length of 1.786(6) $\AA$. The corresponding RuC37-C38 angle is rather large at $136.2(5)^{\circ}$. The phenyl substituent at the carbene carbon atom is oriented toward the pyridine sector.

The chelate ligand at the base of the coordination polyhedron is bonded to $\mathrm{Ru}$ through the pyridine nitrogen (N1-Ru: 2.027(5) $\AA$ ), a carboxamido oxygen (O23-Ru: 2.073(4) $\AA$ ) and a carboxamido nitrogen atom (N9-Ru: 2.100(4) $\AA$ ). The C7-N9 linkage of the latter is found at $1.353(7) \AA$, and the adjacent $\mathrm{C} 7-\mathrm{O} 8$ bond is short (1.236(7) $\AA$ ). The distal O-bonded carboxamido moiety features a short $\mathrm{C}=\mathrm{N}$ linkage (C22-N24: 1.280(7) $\AA$ ) adjacent to an elongated $\mathrm{C}-\mathrm{O}$ bond (C22-O23: 1.322(6) $\mathrm{A}$ ). The planes of the 2,6-diisopropylphenyl substituents at both nitrogen centres are oriented close to normal to the mean basal plane (dihedral angles $\mathrm{C} 26-\mathrm{C} 25-\mathrm{N} 24$ C22: $\left.-74.7(8)^{\circ}, \mathrm{C} 11-\mathrm{C} 10-\mathrm{N} 9-\mathrm{C} 7: 88.5(6)^{\circ}\right)$. The remaining coordination site at the base of complex $\mathrm{N}, \mathrm{N}, \mathrm{O}-4$ is occupied by the $\mathrm{PCy}_{3}$ ligand (Ru-P1: $2.376(2) \AA$ ). The sum of the bond angles at the base is $355.0^{\circ}$ with individual angles of $78.0(2)^{\circ}$ (N1$\mathrm{Ru}-\mathrm{O} 23), 77.8(2)^{\circ}$ (N1-Ru-N9), 108.8(1) ${ }^{\circ}$ (N9-Ru$\mathrm{P} 1)$, and $90.4(1)^{\circ}$ (P1-Ru-O23). The angles of the $\mathrm{Ru}-\mathrm{C} 37$ (metal-carbene) vector to the base atoms amount to $97.8(2)^{\circ}$ (C37-Ru-N1), 102.0(2) ${ }^{\circ}$ (C37$\mathrm{Ru}-\mathrm{N} 9)$, 97.0(2) ${ }^{\circ}$ (C37-Ru-P1), and 96.4(2) ${ }^{\circ}$ (C37$\mathrm{Ru}-\mathrm{O} 23)$.

The chemistry of the more symmetrical O,N,O-4 isomer was also studied, but this compound is more sensitive and its chemistry slightly more complicated.
The O,N,O-4 isomer is much less soluble in pentane and in our typical workup procedure, therefore, it was recovered enriched from the residue after the pentane extraction step. From the reaction of the dipotassium salt $\mathbf{1}$ with $\mathbf{3 a}$ in THF at $r$.t. we recovered a solid material in $c a .40 \%$ yield that apparently was slightly contaminated O,N,O-4. Extraction of this material with $\left[\mathrm{D}_{6}\right]$ benzene or $\left[\mathrm{D}_{2}\right]$ dichloromethane gave rather clean solutions of O,N,O-4 for the NMR analysis. The compound features a ${ }^{31} \mathrm{P}$ NMR signal at $\delta=41.5$ in $\left[\mathrm{D}_{6}\right]$ benzene and shows the typical NMR signals of the $[\mathrm{Ru}]=\mathrm{CH}(\mathrm{Ph})$ unit $\left({ }^{1} \mathrm{H}: \delta=18.88(\mathrm{~d}\right.$, $\left.{ }^{3} J_{\mathrm{P}, \mathrm{H}}=20.9 \mathrm{~Hz}, 1 \mathrm{H}\right)$, see $\mathrm{O}, \mathrm{N}, \mathrm{O}-2$ for a comparison: $\delta=18.21(\mathrm{~d}, 27.5 \mathrm{~Hz}))$. Due to the higher symmetry, complex O,N,O-4 shows only two pyridine signals at $\delta=7.87$ (d) and $\delta=6.85$ (t) in a 2:1 intensity ratio. Again, the planes of the 2,6-diisopropylphenyl substituents seem to be perpendicular to the major ligand plane. At sufficiently low temperature each of the symmetry-equivalent pairs of 2,6-diisopropylphenyl units at the nitrogen atoms features two separate ${ }^{1} \mathrm{H}$ NMR isopropyl- $C H$ septets (at $\delta=3.42$ and $\delta=$ 3.05; cf. O,N,O-2: $\delta=3.36 / 3.01$ (each broad) [3]) and two pairs of isopropyl- $\mathrm{CH}_{3}$ doublets $(\delta=1.42(6 \mathrm{H})$, $\delta=1.20(3 \mathrm{H}), \delta=0.95(3 \mathrm{H}))$ due to the resulting elements of axial chirality. Again, the ${ }^{1} \mathrm{H}$ NMR resonances of the $\mathrm{PCy}_{3}$ ligand are broad, probably due to exchange. The $\mathrm{O}, \mathrm{N}, \mathrm{O}-\mathbf{4}$ complex is thermolabile, it rearranged within several hours at ambient temperature in $\left[\mathrm{D}_{6}\right]$ benzene solution to yield the corresponding N,N,O-4 isomer (Fig. 2).

We were able to get an X-ray crystal structure analysis of a closely related chelate pincer ruthenium carbene complex which was formed by the related salt metathesis reaction starting from $\mathbf{3 b}$ (Scheme 3). In this case we treated the $(\mathrm{NHC})\left(\mathrm{PCy}_{3}\right) \mathrm{Cl}_{2} \mathrm{Ru}=\mathrm{CHPh}$ 


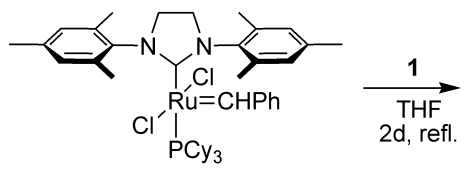

3b

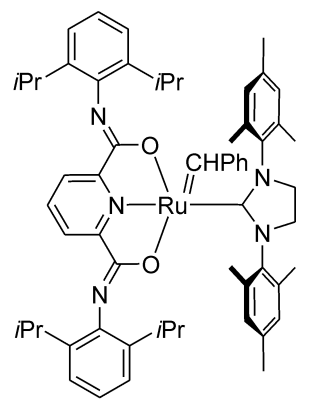

$\mathrm{O}, \mathrm{N}, \mathrm{O}-5$ (single crystals)

Scheme 3.

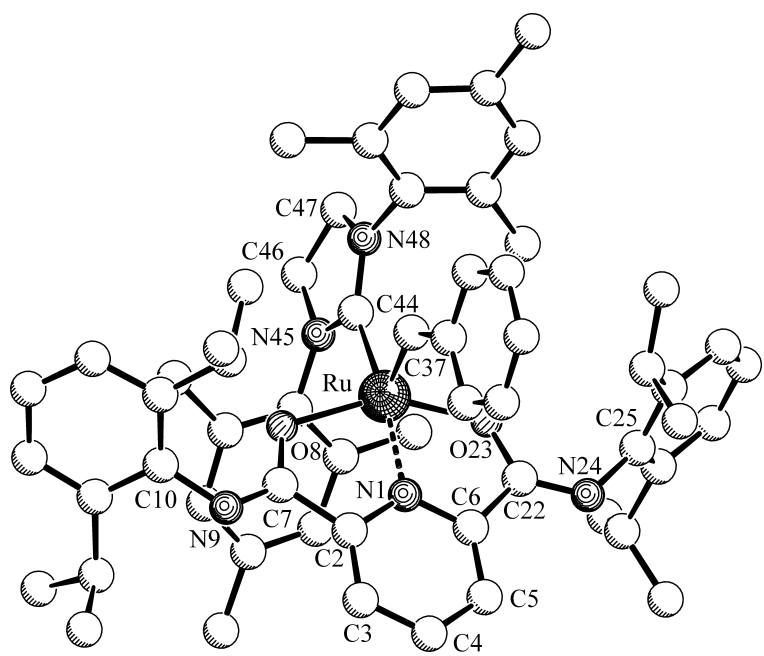

Fig. 3. Molecular structure of O,N,O-5 (hydrogen atoms omitted for clarity).

carbene complex $(\mathbf{3 b})$ with the "dianionic" reagent $\mathbf{1}$ in THF for $2 \mathrm{~d}$ at reflux temperature. After workup we isolated single crystals of the complex O,N,O-5 from a pentane solution. So far, the compound in our hands was too sensitive to be fully characterized in solution.

Complex O,N,O-5 features a distorted squarepyramidal coordination geometry around the ruthenium metal center (Fig. 3). The tridentate pyridine2,6-dicarboxamido ligand and the NHC ligand occupy the four base positions, and the $=\mathrm{CHPh}$ carbene ligand resides in the apical coordination position. The sum of the bond angles at the base is $355.1^{\circ}$. As expected, the O8/O23-Ru-N1 angles within the pincer moiety are slightly smaller $\left(78.1(1)^{\circ} / 78.4(1)^{\circ}\right)$ than the adjacent O8/O23-Ru-C44 angles to the NHC carbene ligand $\left(99.7(1)^{\circ} / 98.9(1)^{\circ}\right)$. The $\mathrm{Ru}-\mathrm{O} 8 / \mathrm{O} 23$ bond lengths amount to 2.047(2) $\AA / 2.058$ (2) $\AA$ and the $\mathrm{Ru}-\mathrm{N} 1$ bond to the pyridine moiety inside the close to
$C_{S}$-symmetric framework is 2.011(3) $\AA$ long. The carboxamido units both feature long $\mathrm{C}-\mathrm{O}$ and short $\mathrm{C}=\mathrm{N}$

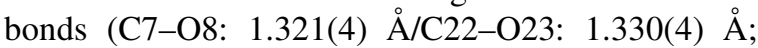

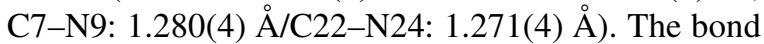
between the ruthenium center and the NHC ligand is relatively long (Ru-C44: 2.044(4) A), whereas the apical $=\mathrm{CHPh}$ carbene ligand features a much shorter $\mathrm{Ru}-\mathrm{C} 37$ linkage $(1.823(3) \AA)$. The $\mathrm{Ru}=\mathrm{CHPh}$ plane is close to the (NHC) C44-Ru-N1 plane and the phenyl substituent at the carbene center (angle Ru-C37-C38: $\left.136.5(3)^{\circ}\right)$ is oriented syn to the pyridine moiety. The apical $=\mathrm{CHPh}$ carbene ligand is, however, slightly tilted away from the pyridine ligand (angles C37-RuN1: $102.0(1)^{\circ}, \mathrm{C} 37-\mathrm{Ru}-\mathrm{C} 44:$ 92.8(2) ${ }^{\circ}, \mathrm{C} 37-\mathrm{Ru}-\mathrm{O} 8$ : 99.9(1) ${ }^{\circ}, \mathrm{C} 37-\mathrm{Ru}-\mathrm{O} 23$ : $\left.100.2(1)^{\circ}\right)$.

The plane of the NHC ligand is oriented close to perpendicular to the mean basal plane of the complex (dihedral angles O8-Ru-C44-N48: 114.6(4) ${ }^{\circ}, \mathrm{O} 23-\mathrm{Ru}-$ C44-N45: $90.6(3)^{\circ}, \quad$ C37-Ru-C44-N48: $\left.14.1(5)^{\circ}\right)$. The planes of the 2,6-diisopropylphenyl substituents at the nitrogen atoms N9/N24 are oriented almost normal to their respective carboxamido planes (dihedral angles O8-C7-N9-C10: -4.2(5) ${ }^{\circ}$, C7-N9-C10-C11: 118.7(4) ${ }^{\circ}$; O23-C22-N24-C25: 3.9(5) ${ }^{\circ}$, C22-N24C25-C26: $\left.85.6(4)^{\circ}\right)$. In the solid state this conformational arrangement makes these aryl-carboxamido units axially chiral. In the crystal these two chiral units feature opposite configurations with both 2,6diisopropylphenyl groups oriented syn relative to the $[\mathrm{Ru}]=\mathrm{CHPh}$ apex: complex O,N,O-5 features a mesotype structure in the solid state (although not imposed by crystallographic symmetry).<smiles>O=C(N[Ga])c1cccc(C(=O)N([Al])Cc2ccccc2)n1</smiles>

$\mathrm{Ar}=-2,6$-diisopropylphenyl

Scheme 4.

In our hands these carbene complexes and/or some of the reaction intermediates proved to be surprisingly hydrolysis sensitive and prone to give side reactions. This is illustrated by the example of the reaction of $\mathrm{Cl}_{2}\left(\mathrm{PCy}_{3}\right)_{2} \mathrm{Ru}=\mathrm{CHPh}$ with 1 in $\mathrm{THF}$ at ambient temperature. From the second pentane extract we isolated single crystals of an unexpected product (6) that turned out to be a molecular mixture of the N-benzylated ligand system admixed in a $1: 1$ ratio with its mono-potassium salt (Scheme 4). It appears 


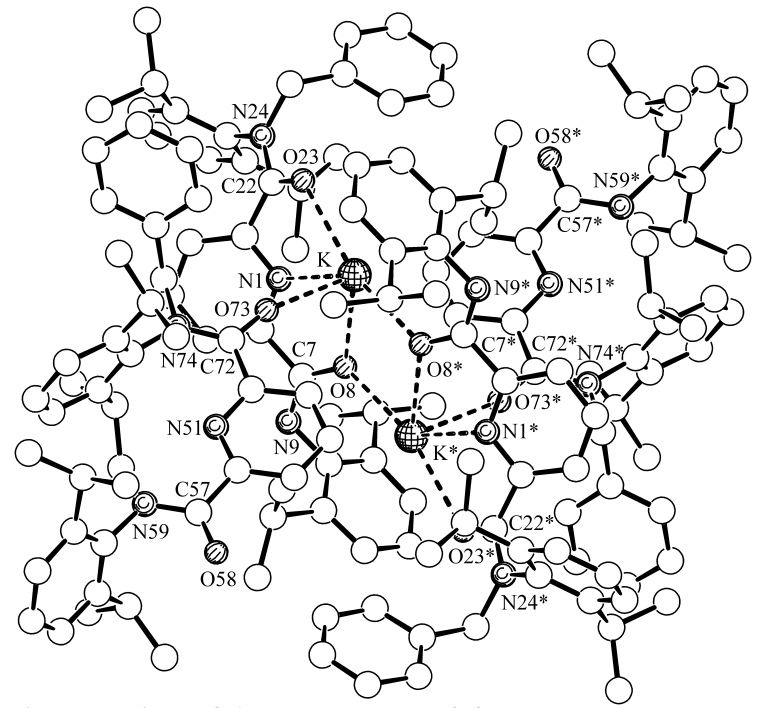

Fig. 4. A view of the components of 6 .

that the $=\mathrm{CHPh}$ ligand at the ruthenium atom had at some stage attacked the pyridine-biscarboxamido ligand and formed a new $\mathrm{C}-\mathrm{N}$ bond. Such ligand attachments to carbene ligands had previously been observed in other cases [10], but are relatively rare. A view of the molecular structure of $\mathbf{6}$ is shown in Fig. 4. It features a mono-anionic ligand that contains a delocalized carboxamido unit (C7-N9:

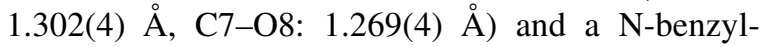
substituted neutral carboxamide unit at the opposite end of the molecular entity (C22-N24: 1.357(4) $\AA$, C22-O23: 1.225(4) $\AA$ ). In addition, there is a neutral component of the same composition, but proto-

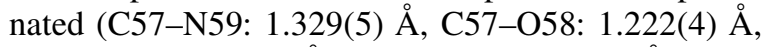

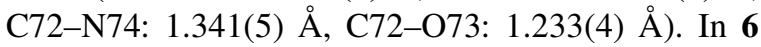
the potassium ion is coordinated to the chelate pincer moiety of the anionic ligand (lig 1-Bn ${ }^{-}$) through both oxygen atoms and the pyridine nitrogen atoms $(\mathrm{K}-\mathrm{O} 8$ :

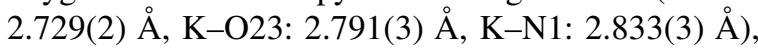
to $\mathrm{O} 8(\# 1)$ of the neighboring (lig $\left.1-\mathrm{Bn}^{-} \# 1\right)(\mathrm{K}-\mathrm{O} 8 \# 1$ : 2.662(2) $\AA$ ) and to O73 of the neutral ligand (lig 1Bn) (K-O73: 2.581(3) $\AA$ ). There are four relatively close contacts of $(\mathrm{K \# 1})^{+}$to the 2,6-diisopropylphen-

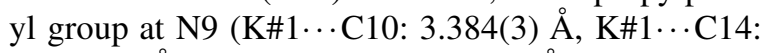

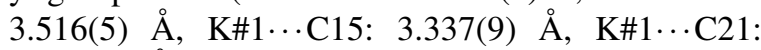
3.396(6) A). The distance between the potassium atoms is large $(\mathrm{K} \cdots \mathrm{K} \# 1: 4.123(2) \AA)$. The coordination geometry of $\mathrm{K}^{+}$in $\mathbf{6}$ can be described as very strongly distorted square-pyramidal. The monoanionic $\mathrm{O}, \mathrm{N}, \mathrm{O}$ - chelate pincer system plus O8\#1 of the next ligand (lig 1-Bn \#1) form the basis (sum of bonding

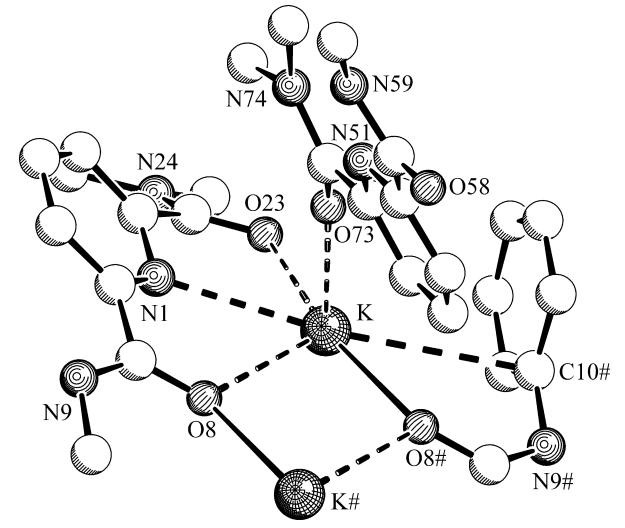

Fig. 5. A schematic view of the coordination geometry around $\mathrm{K}^{+}$in $\mathbf{6}$.

angles $360.1^{\circ}$ ) with $\mathrm{O} 73$ being located at the apical position (bond angles O73-K-O8\#1: 93.2(1) ${ }^{\circ}$, O73$\mathrm{K}-\mathrm{O} 8$ : $86.5(1)^{\circ}$, O73-K-N1: 79.6(1) ${ }^{\circ}, \mathrm{O} 73-\mathrm{K}-\mathrm{O} 23$ : $\left.94.0(1)^{\circ}\right)$ (Fig. 5).

\section{Some Conclusions}

This study has shown that ruthenium carbene complexes with chelate pincer ligands on the basis of the tridentate pyridine-2,6-dicarboxamido ligand can be obtained by treatment of either $\mathrm{Cl}_{2}\left(\mathrm{PCy}_{3}\right)_{2} \mathrm{Ru}=\mathrm{CHPh}$ (3a) or $\mathrm{Cl}_{2}(\mathrm{NHC})\left(\mathrm{PCy}_{3}\right) \mathrm{Ru}=\mathrm{CHPh}(\mathbf{3 b})$ with the corresponding dianionic ligand system $\mathbf{1}$. The products show interesting structural and stereochemical features. However, the reaction is considerably more complex than anticipated. We had previously proposed that complex O,N,O-4 is obtained from the reaction of $\mathbf{1}$ with $\mathbf{3 a}$ in dichloromethane [3]. This erroneous assignment has now been revised by the description of our recent results in the present account. The salt metathesis pathway turned out to be solvent dependent, and the nature of the products also seems to depend strongly on the specific conditions. From our observations it can generally be assumed that two coordination modes of the tridentate ligand prevail. Although a detailed mechanistic study must be awaited, it seems that a rather reactive O,N,O-complex is formed under specific conditions which subsequently is transformed to more stable products characterized by the less symmetric N,N,Ocoordination mode. So far, the new examples of the pincer carbene complexes proved unreactive in olefin metathesis experiments using 1,7-octadiene, leading only to isomerization of the substrate at elevated temperatures. 


\section{Experimental Section}

All reactions with organometallic compounds were carried out under argon using Schlenk-type glassware or a glovebox. Solvents were dried under argon prior to use. The complexes $\mathbf{3 a}$ and $\mathbf{3 b}$ were used as purchased. The ligand system 1 was prepared as previously described [3]. Data sets were collected with Nonius KappaCCD diffractometers, in case of Mo radiation equipped with a rotating anode generator. Programs used: data collection COLLECT [11], data reduction DENZO-SMN [12], absorption correction SORTAV [13] and DENZO [14], structure solution SHELXS-97 [15], structure refinement SHELXL-97 [16], molecular graphics SCHAKAL [17].

CCDC 633063, 633064 and 634451 contain the supplementary crystallographic data for this paper. These data can be obtained free of charge from The Cambridge Crystallographic Data Centre via www.ccdc.cam.ac.uk/data_request /cif.

\section{Reaction of 1 with $3 a$, preparation of $N, N, O-4$}

The reagents $1 \times 2$ THF ( $480 \mathrm{mg}, 0.68 \mathrm{mmol}), 3 a$ (558 mg, $0.68 \mathrm{mmol}$ ) and $\mathrm{PCy}_{3}(189 \mathrm{mg}, 0.68 \mathrm{mmol})$ were mixed in a glove box. The mixture was cooled to $-78^{\circ} \mathrm{C}$ and then THF $(20 \mathrm{~mL})$ was added through a septum via syringe. The mixture was allowed to warm to r.t. and then stirred for $2 \mathrm{~d}$. Solvent was removed from the red-brown mixture in vacuo and the residue extracted several times with pentane (total volume $\sim 50 \mathrm{~mL}$ ). The combined pentane extracts were kept at $0{ }^{\circ} \mathrm{C}$ for $2 \mathrm{~h}$ and then at $-20^{\circ} \mathrm{C}$ overnight. The solution was carefully removed via syringe. The remaining solid was dried in vacuo to give $0.20 \mathrm{~g}(30 \%)$ of N,N,O-4. Anal. calcd. for $\mathrm{C}_{56} \mathrm{H}_{76} \mathrm{~N}_{3} \mathrm{O}_{2} \mathrm{PRu}$ (955.28): C 70.41, H 8.02, $\mathrm{N} 4.40$; found $\mathrm{C} 69.94, \mathrm{H} 8.18, \mathrm{~N} 3.75$. Concentration of the pentane extract to $8 \mathrm{~mL}$ and storage overnight at $-20{ }^{\circ} \mathrm{C}$ gave another $0.10 \mathrm{~g}$ fraction of a $c a .1: 1 \mathrm{~N}, \mathrm{~N}, \mathrm{O}-4 / \mathrm{PCy}_{3}$ mixture. The original pentane insoluble residue was further extracted with $20 \mathrm{~mL}$ of diethyl ether to give $0.2 \mathrm{~g}$ of N,N,O-4 contaminated with probably partially hydrolyzed $\mathbf{1}$. Spectroscopic characterization of N,N,O-4 (with assignments supported by $2 \mathrm{D}$ NMR experiments): ${ }^{1} \mathrm{H}$ NMR $(600 \mathrm{MHz}$, $\left.\mathrm{C}_{6} \mathrm{D}_{6}, 298 \mathrm{~K}\right): \delta=19.45\left(\mathrm{~d},{ }^{3} J_{\mathrm{PH}}=24.1 \mathrm{~Hz}, 1 \mathrm{H},=\mathrm{CH}\right)$; $7.82(\mathrm{~d}), 7.76(\mathrm{~d}), 6.84(\mathrm{t})\left(\right.$ each ${ }^{3} J_{\mathrm{HH}}=7.8 \mathrm{~Hz}$, each $1 \mathrm{H}$, pyridine); $7.22\left(\mathrm{dd}, J_{\mathrm{HH}}=7.5,1.5 \mathrm{~Hz}\right), 7.15,7.10\left(\mathrm{t}, J_{\mathrm{HH}}=\right.$ $7.5 \mathrm{~Hz}$ ) (each $\left.1 \mathrm{H},{ }^{i \mathrm{Pr} 2} \mathrm{C}_{6} \mathrm{H}_{3}{ }^{\mathrm{A}}\right) ; 7.19$ (dd), 7.15, 7.07 (dd) $\left(\right.$ each $J_{\mathrm{HH}}=7.8,1.5 \mathrm{~Hz}$, each $\left.1 \mathrm{H},{ }^{i P r 2} \mathrm{C}_{6} \mathrm{H}_{3}{ }^{\mathrm{B}}\right) ; 7.05(\mathrm{~m}, 1 \mathrm{H}$, p-Ph); 7.04 (m, 2H, o-Ph); 6.93 (m, 2H, $m$-Ph); 3.71 (sept., $1 \mathrm{H}), 1.55(\mathrm{~d}, 3 \mathrm{H}), 1.46(\mathrm{~d}, 3 \mathrm{H})\left(\right.$ each $\left.^{3} J_{\mathrm{HH}}=7.0 \mathrm{~Hz}, i \mathrm{Pr}^{\mathrm{B}}\right)$; 3.33 (sept., $1 \mathrm{H}), 1.43(\mathrm{~d}, 3 \mathrm{H}), 1.39(\mathrm{~d}, 3 \mathrm{H})\left(\right.$ each ${ }^{3} J_{\mathrm{HH}}=$ $\left.6.9 \mathrm{~Hz}, i \operatorname{Pr}^{\mathrm{A}}\right) ; 2.83$ (sept., $\left.1 \mathrm{H}\right), 1.11(\mathrm{~d}, 3 \mathrm{H}), 0.77(\mathrm{~d}, 3 \mathrm{H})$ $\left(\right.$ each $\left.{ }^{3} J_{\mathrm{HH}}=6.9 \mathrm{~Hz}, i \operatorname{Pr}^{\mathrm{A}}\right) ; 2.51$ (sept., $\left.1 \mathrm{H}\right), 1.12(\mathrm{~d}, 3 \mathrm{H})$, $0.78(\mathrm{~d}, 3 \mathrm{H})\left(\right.$ each $\left.{ }^{3} J_{\mathrm{HH}}=7.1 \mathrm{~Hz}, i \operatorname{Pr}^{\mathrm{B}}\right) .-{ }^{13} \mathrm{C}\left\{{ }^{1} \mathrm{H}\right\} \mathrm{NMR}$ $\left(600 \mathrm{MHz}, \mathrm{C}_{6} \mathrm{D}_{6}, 298 \mathrm{~K}\right): \delta=296.1\left(\mathrm{~d},{ }^{3} J_{\mathrm{PC}}=13.6 \mathrm{~Hz}\right.$,
$=\mathrm{CH}) ; 174.6\left(\mathrm{~d},{ }^{3} J_{\mathrm{PC}}=2.5 \mathrm{~Hz}, \mathrm{C}=\mathrm{O}\right) ; 163.5\left(\mathrm{~d},{ }^{3} J_{\mathrm{P}, \mathrm{C}}=\right.$ $4.6 \mathrm{~Hz}, \mathrm{C}=\mathrm{N}) ; 156.0\left(\mathrm{~d},{ }^{4} J_{\mathrm{PC}}=1.6 \mathrm{~Hz}, \mathrm{C}_{\alpha, \mathrm{pyr}}\right) ; 154.5$ $(i-\mathrm{Ph}) ; 152.9\left(\mathrm{~d},{ }^{4} J_{\mathrm{PC}}=0.5 \mathrm{~Hz}, \mathrm{C}_{\alpha, \mathrm{pyr}}\right) ; 137.9\left(\mathrm{C}_{\gamma, \mathrm{pyr}}\right) ; 125.0$ $\left(\mathrm{C}_{\beta, \mathrm{pyr}}\right) ; 124.2\left(\mathrm{C}_{\beta, \mathrm{pyr}}\right) ; 138.1\left(\mathrm{C}_{i \mathrm{Pr}}\right), 137.9\left(\mathrm{C}_{i \mathrm{Pr}}\right), 146.2(\mathrm{C})$, $125.9(\mathrm{CH}), 122.7(\mathrm{CH}), 122.0(\mathrm{CH})\left({ }^{i \mathrm{Pr} 2} \mathrm{C}_{6} \mathrm{H}_{3}{ }^{\mathrm{A}}\right) ; 150.4(\mathrm{C})$, $145.8\left(\mathrm{C}_{i \mathrm{Pr}}\right), 144.2\left(\mathrm{C}_{i \mathrm{Pr}}\right), 124.6(\mathrm{CH}), 123.0(\mathrm{CH}), 122.8$ (CH) $\left({ }^{i \mathrm{Pr} 2} \mathrm{C}_{6} \mathrm{H}_{3}{ }^{\mathrm{B}}\right) ; 129.5(m-\mathrm{Ph}) ; 128.1(p-\mathrm{Ph}) ; 126.1(o-$ $\mathrm{Ph})$; 29.4, 26.6, $24.9\left(i \operatorname{Pr}^{\mathrm{B}}\right) ; 29.2,24.2,22.7\left(i \operatorname{Pr}^{\mathrm{A}}\right) ; 29.1$, 23.3, $22.7\left(i \operatorname{Pr}^{\mathrm{A}}\right) ; 26.8,25.5,22.9\left(i \operatorname{Pr}^{\mathrm{B}}\right) .-{ }^{31} \mathrm{P}\left\{{ }^{1} \mathrm{H}\right\}$ NMR $\left(243 \mathrm{MHz}, \mathrm{C}_{6} \mathrm{D}_{6}, 298 \mathrm{~K}\right): \delta=26.3 .{ }^{1} \mathrm{H}$ and ${ }^{13} \mathrm{C}$ signals of the cyclohexyl unit of the phosphine could not be unambiguously assigned. The ${ }^{13} \mathrm{C}=\mathrm{O}$ and ${ }^{13} \mathrm{C}=\mathrm{N}$ resonances were assigned according to data of $[\mathrm{Ru}]$ complexes described in reference [8].

\section{$X$-Ray structure determination of $\mathrm{N}, \mathrm{N}, \mathrm{O}-4$}

Single crystals of N,N,O-4 suitable for X-ray crystal structure analysis were obtained from a pentane solution at $6{ }^{\circ} \mathrm{C}$ : formula $\mathrm{C}_{56} \mathrm{H}_{76} \mathrm{~N}_{3} \mathrm{O}_{2} \mathrm{PRu} \cdot 1 / 2 \mathrm{C}_{5} \mathrm{H}_{12}, M=991.31$, yellow crystal $0.25 \times 0.15 \times 0.02 \mathrm{~mm}, a=18.2946(4)$, $b=14.6772(4), c=21.6430(5) \AA, \beta=105.841(2)^{\circ}, V=$ $5590.7(2) \AA^{3}, \rho_{\text {calc }}=1.178 \mathrm{~g} \mathrm{~cm}^{-3}, \mu=2.849 \mathrm{~mm}^{-1}$, empirical absorption correction $(0.536 \leq T \leq 0.945), Z=4$, monoclinic, space group $P 2{ }_{1} / c$ (No. 14), $\lambda=1.54178 \AA$, $T=223 \mathrm{~K}, \omega$ and $\varphi$ scans, 38911 reflections collected $( \pm h, \pm k, \pm l),((\sin \theta) / \lambda)=0.60 \AA^{-1}, 9849$ independent $\left(R_{\text {int }}=0.079\right)$ and 7762 observed reflections $(I \geq 2 \sigma(I)), 596$ refined parameters, $R=0.068, w R^{2}=0.176$, max. $/ \mathrm{min}$. residual electron density $1.16 /-0.64$ e $\AA^{-3}$, solvent molecule refined with geometrical constraints and isotropic thermal parameters, hydrogen atoms calculated and refined as riding atoms.

\section{Preparation of $\mathrm{O}, \mathrm{N}, \mathrm{O}-4$ for $\mathrm{NMR}$ experiments}

The reagents 1 (250 mg, $0.44 \mathrm{mmol})$ and 3a $(369 \mathrm{mg}$, $0.44 \mathrm{mmol})$ were mixed in THF $(50 \mathrm{~mL})$ at r.t. and stirred for $2 \mathrm{~d}$. Volatiles were removed in vacuo and the residue triturated with pentane overnight at r.t. The crude material was collected by filtration and the trituration with pentane was repeated twice to give a brown amorphous solid after filtration and drying in vacuo, which may still have contained some $\mathrm{KCl}$; yield $183 \mathrm{mg}$ ( $\mathrm{ca}$. $40 \%)$. Extraction of small samples of this material with $\left[\mathrm{D}_{6}\right]$ benzene (or with $\left[\mathrm{D}_{2}\right]$ dichloromethane) gave solutions of clean O,N,O4 which were used for the NMR spectroscopic characterization. ${ }^{1} \mathrm{H}$ NMR $\left(600 \mathrm{MHz}, \mathrm{C}_{6} \mathrm{D}_{6}, 298 \mathrm{~K}\right): \delta=18.88$ (d, $\left.{ }^{3} J_{\mathrm{P}, \mathrm{H}}=20.9 \mathrm{~Hz}, 1 \mathrm{H},=\mathrm{CH}\right) ; 7.87(\mathrm{~d}, 2 \mathrm{H}), 6.85(\mathrm{t}, 1 \mathrm{H})$ (each ${ }^{3} J_{\mathrm{HH}}=7.8 \mathrm{~Hz}$, pyridine); $3.42(2 \mathrm{H}), 3.05(2 \mathrm{H}), 1.42$ $(12 \mathrm{H}), 1.20(6 \mathrm{H}), 0.95(6 \mathrm{H})$ (each broad, $i \mathrm{Pr}) .-{ }^{31} \mathrm{P}\left\{{ }^{1} \mathrm{H}\right\}$ NMR (243 MHz, $\left.\mathrm{C}_{6} \mathrm{D}_{6}, 298 \mathrm{~K}\right): \delta=41.5 .-{ }^{1} \mathrm{H},{ }^{31} \mathrm{P}$ ghmbc (600/243 MHz, $\left.\mathrm{C}_{6} \mathrm{D}_{6}, 298 \mathrm{~K}\right): \delta^{31} \mathrm{P} / \delta^{1} \mathrm{H}=41.5 / 18.88,2.10$, $1.82,1.34\left(\mathrm{PR}_{3} /=\mathrm{C} H, \mathrm{P}\left(\mathrm{C}_{6} H_{11}\right)_{3}\right) .-{ }^{1} \mathrm{H}$ NMR $(600 \mathrm{MHz}$, 
$\left.\mathrm{CD}_{2} \mathrm{Cl}_{2}, 213 \mathrm{~K}\right): \delta=18.58\left(\mathrm{~d},{ }^{3} J_{\mathrm{PH}}=22.5 \mathrm{~Hz}, 1 \mathrm{H},=\mathrm{CH}\right)$; $8.15(\mathrm{~d}, 2 \mathrm{H}), 8.04(\mathrm{t}, 1 \mathrm{H})\left(\right.$ each ${ }^{3} J_{\mathrm{HH}}=7.9 \mathrm{~Hz}$, pyridine $)$; 7.39 (m, 1H, p-Ph); 7.19 (m, 2H, $m-\mathrm{Ph}) ; 7.12$ (m, 2H, o-Ph); $6.96\left(\mathrm{dd}, J_{\mathrm{HH}}=7.5,1.4 \mathrm{~Hz}\right), 6.88\left(\mathrm{dd}, J_{\mathrm{HH}}=7.5,1.4 \mathrm{~Hz}\right)$, $6.85\left(\mathrm{t}, J_{\mathrm{HH}}=7.5 \mathrm{~Hz}\right)\left(\right.$ each $\left.1 \mathrm{H},{ }^{i \operatorname{Pr} 2} \mathrm{C}_{6} \mathrm{H}_{3}\right) ; 2.83$ (sept., $\left.2 \mathrm{H}\right)$, $1.05(\mathrm{~d}, 12 \mathrm{H})\left(\right.$ each $\left.^{3} J_{\mathrm{HH}}=6.8 \mathrm{~Hz}, i \mathrm{Pr}\right) ; 2.58$ (sept., $\left.2 \mathrm{H}\right), 0.87$ $(\mathrm{d}, 6 \mathrm{H}), 0.49(\mathrm{~d}, 6 \mathrm{H})\left(\right.$ each $\left.{ }^{3} J_{\mathrm{HH}}=6.9 \mathrm{~Hz}, i \mathrm{Pr}\right) .-{ }^{13} \mathrm{C}\left\{{ }^{1} \mathrm{H}\right\}$ NMR (600 MHz, $\left.\mathrm{C}_{6} \mathrm{D}_{6}, 298 \mathrm{~K}\right): \delta=290.6(=\mathrm{CH}) ; 137.6$, 123.5 (pyridine); $128.5(m-\mathrm{Ph}) ; 127.7(p-\mathrm{Ph}) ; 125.2(o-\mathrm{Ph})$; 121.8, 121.7, $121.3\left({ }^{i \mathrm{Pr} 2} \mathrm{C}_{6} \mathrm{H}_{3}\right) ; 28.2,23.0,22.6$ (iPr); 27.7, 23.6, 22.0 ( $i \mathrm{Pr}$ ) (the ${ }^{13} \mathrm{C}$ resonances were obtained by ghsqc experiments). The ${ }^{1} \mathrm{H}$ and ${ }^{13} \mathrm{C}$ signals of the cyclohexyl unit of the phosphine could not be located unambiguously.

\section{Preparation of $\mathrm{O}, \mathrm{N}, \mathrm{O}-4$ on a semi preparative scale}

The dipotassium salt 1 (318 $\mathrm{mg}, 0.57 \mathrm{mmol})$ and complex 3a (470 mg, $0.57 \mathrm{mmol})$ were mixed in tetrahydrofuran $(100 \mathrm{~mL})$ at r.t. and stirred for $2 \mathrm{~d}$. Then all volatiles were removed in vacuo, toluene $(40 \mathrm{~mL})$ was added and the suspension was quickly filtered over celite to remove potassium chloride. All volatiles were removed in vacuo and the residue was triturated by stirring in pentane $(40 \mathrm{~mL})$ for $2 \mathrm{~h}$ at r.t. The supernatant was removed and the remaining solid was washed again with pentane $(2 \times 40 \mathrm{~mL})$. After drying in vacuo $84 \mathrm{mg}$ ( $24 \%$, red-brown solid) product were obtained. Anal. calcd. for $\mathrm{C}_{56} \mathrm{H}_{76} \mathrm{~N}_{3} \mathrm{O}_{2} \mathrm{PRu}$ (955.28): $\mathrm{C} 70.41, \mathrm{H} \mathrm{8.02}$, N 4.40; found C 68.74, H 7.77, N 4.45.

\section{X-Ray structure determination of $\mathrm{O}, \mathrm{N}, \mathrm{O}-5$}

The reagent $1 \times 2 \mathrm{THF}(840 \mathrm{mg}, 1.2 \mathrm{mmol}$ ) was reacted with $(\mathrm{NHC})\left(\mathrm{PCy}_{3}\right) \mathrm{Cl}_{2} \mathrm{Ru}=\mathrm{CHPh}(\mathbf{3 b})(558 \mathrm{mg}, 0.59 \mathrm{mmol})$ in $20 \mathrm{~mL}$ THF as described above for the reaction with 3a $(2$ d, r.t.). From the pentane extract single crystals of $\mathrm{O}, \mathrm{N}, \mathrm{O}-5$ were obtained that were used for the $\mathrm{X}$-ray crystal structure analysis: formula $\mathrm{C}_{59} \mathrm{H}_{69} \mathrm{~N}_{5} \mathrm{O}_{2} \mathrm{Ru} \cdot \mathrm{C}_{5} \mathrm{H}_{12}$, $M=1053.41$, dark red crystal $0.20 \times 0.20 \times 0.20 \mathrm{~mm}, a=$ 11.871(1), $b=12.760(1), c=19.999(1) \AA, \alpha=103.22(1)$, $\beta=94.00(1), \gamma=94.89(1)^{\circ}, V=2925.8(3) \AA^{3}, \rho_{\text {calc }}=$ $1.196 \mathrm{~g} \mathrm{~cm}^{-3}, \mu=0.314 \mathrm{~mm}^{-1}$, empirical absorption correction $(0.940 \leq T \leq 0.940), Z=2$, triclinic, space group $P \overline{1}$ (No. 2), $\lambda=0.71073 \AA, T=223 \mathrm{~K}, \omega$ and $\varphi$ scans, 23278 reflections collected $( \pm h, \pm k, \pm l),((\sin \theta) / \lambda)=0.60 \AA^{-1}$, 10278 independent $\left(R_{\text {int }}=0.072\right)$ and 7749 observed reflections $(I \geq 2(I))$, 634 refined parameters, $R=0.054, w R^{2}=$ 0.142 , max./min. residual electron density $0.69 /-0.60 \mathrm{e}^{-3}$, solvent molecule refined with geometrical constraints and common isotropic thermal parameter, hydrogen atoms calculated and refined as riding atoms.

\section{$X$-Ray structure determination of 6}

Single crystals were obtained from a pentane extract of a reaction mixture of $\mathbf{1}$ with $\mathbf{3 a}$ in THF ( 2 d, r.t.): formula $\mathrm{C}_{76} \mathrm{H}_{89} \mathrm{~N}_{6} \mathrm{O}_{4} \mathrm{~K} \cdot 1 / 2 \mathrm{C}_{5} \mathrm{H}_{12}, M=1225.71$, yellow crystal $0.60 \times 0.25 \times 0.10 \mathrm{~mm}, a=15.526(1), b=16.267(1), c=$ 16.488(1) $\AA, \alpha=91.32(1), \beta=103.72(1), \gamma=111.94(1)^{\circ}$, $V=3723.5(4) \AA^{3}, \rho_{\text {calc }}=1.093 \mathrm{~g} \mathrm{~cm}^{-3}, \mu=0.121 \mathrm{~mm}^{-1}$, empirical absorption correction $(0.931 \leq T \leq 0.988), Z=2$, triclinic, space group $P \overline{1}$ (No. 2), $\lambda=0.71073 \AA, T=223 \mathrm{~K}$, $\omega$ and $\varphi$ scans, 41878 reflections collected $( \pm h, \pm k, \pm l)$, $((\sin \theta) / \lambda)=0.62 \AA^{-1}, 15071$ independent $\left(R_{\text {int }}=0.062\right)$ and 8713 observed reflections $(I \geq 2 \sigma(I)), 823$ refined parameters, $R=0.085, w R^{2}=0.263$, max. $/ \mathrm{min}$. residual electron density $0.80 /-0.36 \mathrm{e} \AA^{-3}$, solvent molecule refined with geometrical constraints and isotropic thermal parameters, hydrogen atoms calculated and refined as riding atoms.
[1] S.T. Diver, A. J. Giessert, Chem. Rev. 2004, 104, 1317 -1382; R. H. Grubbs, Tetrahedron 2004, 60 , 7117 -7140; S. J. Connon, S. Blechert, Angew. Chem. 2003, 115, 1944 -1968; Angew. Chem. Int. Ed. 2003, 42, 1900 - 1923; R. R. Schrock, A. H. Hoveyda, Angew. Chem. 2003, 115, 4740-4782; Angew. Chem., Int. Ed. 2003, 42, 4592-4633; R. H. Grubbs, Handbook of Metathesis, VCH-Wiley, Weinheim, 2003; T. M. Trnka, R. H. Grubbs, Acc. Chem. Res. 2001, 34, $18-$ 29.

[2] J.E. Williams, M. J. Harner, M. B. Sponsler, Organometallics 2005, 24, 2013 -2015; T. Ung, A. Hejl, R. H. Grubbs, Y. Schrodi, Organometallics 2004, 23, 5399 5401; T.-L. Choi, R. H. Grubbs, Angew. Chem. 2003, 115, 1785-1788; Angew. Chem. Int. Ed. 2003, 42, 1743 -1746; H. Katayama, C. Wada, K. Taniguchi, F. Owaza, Organometallics 2002, 21, 3285-3291;
A. F. Hill, A. G. Hulkes, A. J. P. White, D. J. Williams, Organometallics 2000, 19, 371-373.

[3] J.-C. Wasilke, G. Wu, X. Bu, G. Kehr, G. Erker, Organometallics 2005. 24, 4289-4297.

[4] P. Schwab, M. B. France, J. W. Ziller, R. H. Grubbs, Angew. Chem. 1995, 107, 2179-2181; Angew. Chem. Int. Ed. 1995, 34, 2039-2041.

[5] K. Tanaka, V.P. W. Böhm, D. Chadwick, M. Roeper, D.C. Braddock, Organometallics 2006, 25, 5696-5698; W. Buchowicz, F. Ingold, J. C. Mol, M. Lütz, A.L. Spetz, Chem. Eur. J. 2001, 7, $2842-$ 2847.

[6] P. E. Schwab, R. H. Grubbs, J. W. Ziller, J. Am. Chem. Soc. 1996, 118, 100-110.

[7] T. M. Trnka, J.P. Morgan, M. S. Sanford, T.E. Wilhelm, M. Scholl, T.-L. Choi, S. Ding, M. W. Day, R. H. Grubbs, J. Am. Chem. Soc. 2003, 125, 2546- 
2558; C. W. Bielawski, R. H. Grubbs, Angew. Chem. 2000, 112, 3025-3028; Angew. Chem. Int. Ed. 2000 , 39, 2903 -2906; M. Scholl, S. Ding, C. W. Lee, R. H. Grubbs, Org. Lett. 1999, 1, 953 - 956.

[8] M. K. Tse, S. Bhor, M. Klawonn, G. Anilkumar, H. Jiao, C. Döbler, A. Spannenberg, W. Mägerlein, H. Hugl, M. Beller, Chem. Eur. J. 2006, 12, $1855-$ 1874; S. M. Redmore, C. E. F. Rickard, S. J. Webb, L. J. Wright, Inorg. Chem. 1997, 36, 4743-4748.

[9] E. L. Eliel, S. H. Wilm, L. N. Mander, Stereochemistry of Organic Compounds, Wiley, New York, 1994, Chapter 14.

[10] C. M. Frech, O. Blacque, H. W. Schmalle, H. Berke, C. Adlhart, P. Chen, Chem. Eur. J. 2006, 12, $3325-$ 3388.

[11] B. V. Nonius, Delft (The Netherlands) 1998.
[12] Z. Otwinowski, W. Minor, Methods in Enzymology 1997, 276, 307-326.

[13] R. H. Blessing, Acta Crystallogr. 1995, A51, 33-37; R. H. Blessing, J. Appl. Crystallogr. 1997, 30, $421-$ 426.

[14] Z. Otwinowski, D. Borek, W. Majewski, W. Minor, Acta Crystallogr. 2003, A59, 228 - 234.

[15] G. M. Sheldrick, SHELXS-97, Program for the Solution of Crystal Structures, University of Göttingen, Göttingen (Germany) 1997. See also: G. M. Sheldrick, Acta Crystallogr. 1990, A46, 467-473.

[16] G. M. Sheldrick, SHELXL-97, Program for the Refinement of Crystal Structures, University of Göttingen, Göttingen (Germany) 1997.

[17] E. Keller, SCHAKAL, University of Freiburg, Freiburg (Germany) 1997. 